\title{
Uma Professora-Artista em Cena: Vivências que mobilizam o pensar na/sobre docência em dança na Educação Básica
}

\author{
Carolina Pinto da Silva \\ Universidade Federal de Pelotas - UFPel, Pelotas/RS, Brasil \\ E-mail: carolpinto.bailarina@gmail.com \\ Josiane Gisela Franken Corrêa \\ Universidade Federal de Pelotas - UFPel, Pelotas/RS, Brasil \\ E-mail: josianefranken@gmail.com
}

\section{Resumo}

O trabalho aborda como tema norteador a formação docente em relação ao ensino de dança na escola de Educação Básica, tendo por objetivo refletir acerca da noção de professora-artista, a partir de estudo teórico, de uma investigação de si (JOSSO, 2007), ou seja, da autora no papel de professora de dança, através de reflexões sobre entrevistas narrativas (JOVCHELOVITCH; BAUER, 2015) realizadas com seis estudantes envolvidos na sua prática profissional. A pesquisa tem como base estudos de autores como: Márcia Strazzacappa (2006; 2011) e Isabel Marques (1999; 2003; 2014), em relação ao ensino de dança na escola; e Patriciane Born (2012), Maria Falkembach (2017), Gilberto Icle e Mônica Torres Bonatto (2017) e Márcia Strazzacappa (2006; 2011) sobre a ideia de professor-artista. Com o desenvolvimento da investigação, foi possível reconhecer e compreender de forma ampliada a contínua constituição docente como professora-artista da dança em atuação em uma escola pública de Educação Básica. E, ainda, identificar fatores artístico-pedagógicos que agem como problematizadores e influenciadores nos processos de ensino e aprendizagem da dança no território escolar, como por exemplo, a experimentação, junto aos alunos, de vivências em que a figura docente transita atuando nos bastidores, na cena e no público em trabalhos de dança, desempenhando papeis diversos da prática artística na escola.

Professora-Artista. Cena. Dança na escola. (Auto)formação.
The work addresses as a guiding theme the teacher training in relation to dance education in the Basic Education school, aiming to reflect on the notion of teacher-artist, from a theoretical study, of an investigation of herself (JOSSO, 2007), that is, the author in the role of dance teacher, through reflections on narrative interviews (JOVCHELOVITCH; BAUER 2015) carried out with six students involved in their professional practice. The research is based on studies by authors such as: Márcia Strazzacappa (2006; 2011) and Isabel Marques (1999; 2003; 2014), in relation to teaching dance at school; and Patriciane Born (2012); Maria Falkembach (2017), Gilberto Icle and Mônica Torres Bonatto (2017) and Márcia Strazzacappa $(2006$; 2011) about the idea of teacher-artist. With the development of the investigation, it was possible to recognize and comprehend in a broader way the continuous teacher constitution as a dance artist-teacher working in a public school of Basic Education. And, yet, to identify artistic-pedagogical factors that act as problematizers and influencers in the teaching and learning processes of dance in the school territory, such as, for example, the experimentation, with the students, of experiences in which the teaching figure transits acting behind the scenes, on the scene and in the audience in dance works, playing different roles of artistic practice at school.

Teacher-Artist. Scene. Dance at school.

(Self)training. 


\section{Introdução}

O texto aqui apresentado é um recorte revisado de um Trabalho de Conclusão de Curso ${ }^{1}$ (TCC) que se volta, de modo amplo, à formação de professores de dança na escola. De modo mais restrito, a investigação trata da noção de professora-artista (STRAZZACAPPA, 2006, 2011), levando em consideração uma reflexão sobre as narrativas que emergem da minha história de vida, em diálogo com narrativas de alguns dos meus alunos e com o estudo teórico.

Partindo do pressuposto de que sou/estou professora-artista em uma escola de Educação Básica, o texto caracteriza-se por um relato de experiência, pois a pesquisa consiste em uma investigação de si (JOSSO, 2007), e parte de alguns questionamentos como, por exemplo: a minha arte interfere/influencia/mobiliza o meu caminho (auto) formativo e a minha docência em dança? Como me entendo e me reconheço como professora-artista a partir do olhar para minha trajetória docente?

Desse modo, neste artigo tenho por objetivo problematizar a noção de professora-artista segundo os teóricos estudados para o desenvolvimento da pesquisa (BORN, 2012; FALKEMBACH, 2017; ICLE; BONATTO, 2017; MARQUES, 2003; MARQUES, 2014; STRAZZACAPPA, 2006; STRAZZACAPPA, 2011) e refletir acerca da relação entre a produção artística e a produção pedagógica na (auto)formação docente em dança. $O$ trabalho tem como foco a análise da minha história de vida e das narrativas de seis estudantes da Escola Estadual de Ensino Médio Areal, de Pelotas RS, em que integro o corpo docente. A produção dos dados analisados foi realizada através de rememoração de acontecimentos que vivenciei formativa e profissionalmente e por meio de entrevistas narrativas (JOVCHELOVITCH; BAUER, 2015).

1 Ensino de Dança e investigação de si: memórias formativas de uma professora-artista, trabalho de conclusão de curso apresentado em 2019 no Curso de Dança - Licenciatura, do Centro de Artes, da Universidade Federal de Pelotas. A pesquisa teve orientação da Prof. ${ }^{a} \mathrm{Dr}^{\mathrm{a}}$. Josiane Franken Corrêa, e avaliação dos professores: Prof. ${ }^{a}$ Dra . Andrisa Kemel Zanella e Prof. Dr. Jeferson de Oliveira Cabral. Link para acesso do texto na íntegra: https:// wp.ufpel.edu.br/danca/trabalhos-de-conclusao/2019-2/.

\section{Ser professora-artista}

No primeiro momento da pesquisa, o enfoque investigativo voltou-se à análise narrativa da minha trajetória profissional de (auto)formação docente, buscando, ao mesmo tempo, refletir e discutir como o termo "professora-artista" foi sendo compreendido por mim durante a atuação docente em dança no contexto escolar que, em 2019, contabilizava mais de 13 anos de prática profissional.

Essas memórias investigadas partiram do trajeto trilhado desde as primeiras experiências como artista da Dança e de minha primeira formação superior, no Curso de Educação Física - Licenciatura (2005) da Universidade Federal de Pelotas (UFPel), dando ênfase à minha inserção na escola como professora de ensino básico, até o momento da minha entrada como acadêmica do curso de Dança - Licenciatura da UFPel.

Trago em princípio reflexões sobre as vivências no curso de Educação Física relacionadas às experiências artísticas desenvolvidas em ambientes não formais de ensino, acreditando que muito da minha (auto)formação docente é atrelada às referências externas à Universidade, como a aprendizagem oportunizada por coreógrafos e professores e seus modos de conduzir práticas artístico-pedagógicas em Dança.

Com os conhecimentos produzidos pelo ambiente universitário e a partir das referências artísticas, ao iniciar a minha carreira como professora de Educação Física no ambiente escolar, sinto-me motivada a trabalhar em projetos de ensino de dança que aconteciam no turno inverso do currículo regular.

Atualmente, ao retomar memórias oriundas das vivências como professora, percebo que, ao ter a oportunidade de cursar uma Graduação em Dança, pude ressignificar concepções sobre a abordagem e atuação do professor de Arte/Dança, a fim de elaborar uma compreensão própria acerca da ideia de professor-artista da Dança na escola de Educação Básica.

Nesse movimento (auto)formativo busquei também assumir, ou me aproximar, do perfil profissional pretendido pelo Curso de Dança no qual me graduei, que tem como um dos seus princípios: "preparar os futuros professores para transitar na sua vida 
profissional entre três vertentes de conhecimento - pedagógica, artística e científica -, assim com o intuito de formar um professor-artista-pesquisador" (PPC, Curso de Dança-Licenciatura da UFPel, 2013).

De todo modo, foi necessário ir além da investigação de si (JOSSO, 2007) já em desenvolvimento para, num segundo momento de pesquisa, aprofundar o estudo de teorias relacionadas à união entre docência e criação artística no ensino de dança.

No caminho investigativo, foi possível encontrar uma série de variações de nomenclaturas para o que, de modo geral, corresponde à prática do professor que também é artista, tais como: professora-artista (STRAZZACAPPA; MORANDI, 2006); (DEBORTOLI, 2011), artista-docente (DE ARAÚJO, 2012); (MARQUES, 2003), professor-performer (ICLE; BONATTO, 2017), professoras artistas (BORN, 2012), artista-professor (PASTE, 2017), entre outros.

Esses termos podem ser encontrados em diversos estudos, ao longo dos últimos anos, relacionados aos campos das artes, entre teatro, dança e artes visuais. Os discursos e práticas que envolvem os fazeres artístico-pedagógicos de docentes e as investigações de pesquisadores debruçados sobre o tema do ensino de arte nas escolas, independente da área artística, fomentam de forma contínua, a elaboração de nomenclaturas novas e atualizadas. Nesse sentido, a criação de termos busca dar conta da ideia de um fazer docente que se estabelece por meio de atividades pedagógicas contaminadas pelo fazer artístico e vice-versa, carregando na sua conceituação a intenção da não separação entre práticas artísticas e educacionais (DE ARAÚJO, 2012).

Acerca do ensino universitário de Teatro, De Araújo (2012) discorre sobre o entendimento do termo artista-docente e aponta que a elaboração do mesmo, parte "da necessidade de se criar um vocabulário em torno da integração entre a prática artística e a educacional", acreditando que a junção dessas funções abre espaço "para a consideração de uma proposta artístico-educativa, na qual a criação e o processo educativo se potencializam" (DE ARAÚJO, 2012, p. 2).
Também no campo das Artes Cênicas, Icle e Bonatto (2017) discutem os "entrelugares" da escola e a experiência performática como meio de "minimizar" a posição hierárquica entre professor e aluno. Os autores utilizam-se da noção de "professor-performer" como sendo "uma proposta de radicalização do processo de ensino-criação, em especial pela flexibilização dos papéis professor/estudante e pela provocação para pensarmos novas formas de atuação na educação básica" (ICLE; BONATTO, 2017, p. 23).

Perobelli (2011), ao investigar o ensino de teatro na escola, compreende a "junção" das palavras de forma que "ao estabelecer a conexão entre artista e docente, por meio de uma ponte criada pelo hífen, estamos propondo uma relação de entrelaçamento das dimensões do artista e do docente em um mesmo Ser" (PEROBELLI, 2011, p. 3).

No campo das Artes Visuais, Born (2012) discute sobre a não dicotomização entre os campos artístico e pedagógico e se propõe a debater acerca dos discursos relacionados ao conceito de artista na escola, como o mito da genialidade artística, por exemplo, e problematiza que existe um "paradoxo" na concepção da arte no ensino formal: "enquanto que, como disciplina, ela [a arte] é historicamente desvalorizada, ao mesmo tempo, há um 'endeusamento' da figura do artista, visto como algo inacessível, estranho no meio escolar" (BORN, 2012, p. 46).

Mais especificamente no campo da Dança, Marques vem traçando relações teórico-práticas entre prática artística e docente desde a década de 1990, lembrando que "[...] dança e educação têm sido historicamente compreendidas pelo senso comum como áreas de conhecimento isoladas, com diálogos frágeis e preconceitos transversalizados. Defendo há mais de 25 anos que dança e educação devem dialogar" (MARQUES, 2014, p. 232).

Para autora, que costumava utilizar o termo artista-docente (MARQUES, 2003) e atualmente adota a expressão artista/docente, a noção desse ser/estar professor-artista na escola diz respeito "[...] aquele que, numa mesma proposta, dança e educa: educa dançando e dança educando, consciente das duas ações fundidas que exerce." (MARQUES, 2014, p. 235). 
Já Strazzacappa (2006), ao abordar transformações na profissão "professor de dança" ao longo do tempo, traz uma importante questão relacionada ao tema: "É possível formar o professor de arte sem antes formar o artista?" (STRAZZACAPPA; MORANDI, 2006, p. 33). A autora enfatiza que para lecionar dança é importante viver esta linguagem artística pela prática, pelo fruir e sentir, assim como se permitir vivenciar processos criativos em dança, mesmo não sendo ou não tendo a intenção de ser um bailarino virtuoso.

Para tanto, Strazzacappa $(2006$; 2011) defende a figura do professor-artista, pois em sua própria experiência reflete a ideia da junção entre ensinar/fazer arte, e declara: "[...] a arte me alimenta e me faz ser uma melhor professora. A docência e a pesquisa me fazem ser uma melhor artista" (STRAZZACAPPA; MORANDI, 2006, p. 57).

\section{Sobre outras vozes na pesquisa: estudantes-espectadores}

Num terceiro momento de pesquisa, convidei estudantes que foram testemunhas da minha prática docente em dança na escola para colaborarem no aprofundamento da discussão investida pelo trabaIho. Para isso, escolhi uma experiência artístico-pedagógica entendida como situação-chave para a reflexão, com o objetivo de investigar nuances do meu caminho formativo que me fazem crer na noção de professora-artista da Dança, estudada na investigação. Entendo situação-chave como um acontecimento importante para a minha constituição profissional, no caso a apresentação de um espetáculo de dança em uma situação específica no território escolar.

A experiência refere-se a uma das apresentações do espetáculo Quando você me toca do Tatá Núcleo de Dança-Teatro ${ }^{2}$, com direção da professora

2 O Tatá Núcleo de Dança-Teatro é um Projeto Unificado vinculado ao Curso de Dança - Licenciatura, da Universidade Federal de Pelotas. O grupo integra atores-bailarinos dos cursos de Dança e Teatro da universidade, com o objetivo de difundir a dança contemporânea, promover a arte-educação, e contribuir com a formação de públi$\mathrm{co}$, visando propor a fruição em escolas públicas. Ver mais em: http://grupotata.blogspot.com/p/o-projeto.html.
Maria Falkembach ${ }^{3}$, do qual faço parte como intérprete-criadora, ocorrida na Escola Estadual de Ensino Médio Areal, em Pelotas RS, na qual atuo como professora.

Os parceiros do estudo são seis alunos da E.E.E.M Areal, escola em que trabalho desde 2014 e onde coordenei um projeto de Dança Contemporânea entre os anos de 2016 a 2018. A seleção foi realizada a partir de um convite para alunos que tinham assistido ao espetáculo Quando você me toca, apresentado no dia 21 de agosto de 2019 no teatro da escola. Posteriormente, foi realizada uma entrevista narrativa (JOVCHELOVITCH; BAUER, 2015), conduzida com base em perguntas disparadoras. $\mathrm{O}$ material narrativo produzido na entrevista foi analisado e dividido em três categorias: "O corpo da professora em exposição", "Feição de artista" e "Nem todo professor de Arte é artista", expostas mais adiante.

A proposta de trazer a narrativa dos estudantes para a pesquisa, em complemento à minha narrativa e à revisão de literatura, partiu do desejo de compreender a percepção deles sobre as questões envolvidas na investigação. Nesse sentido, o trabalho, que iniciou focado na narrativa docente, foi sendo redirecionado para trazer à tona depoimentos dos principais envolvidos nos processos de aprendizagem em dança no ensino formal: os estudantes.

O espetáculo 4 Quando você me toca, utilizado como meio para a produção das narrativas, propõe uma discussão sobre o toque no ambiente escolar e nasceu da identificação de tensões provocadas pelo ensino da dança na escola, tensões percebidas e discutidas por Maria Falkembach (2017) em sua tese que aborda as práticas de dança como componente curricular obrigatório de Arte na educação básica. 3 Professora-artista do Curso de Dança-Licenciatura da
UFPel desde a sua abertura.

4 O espetáculo Quando Você Me Toca tem como proposta explorar a superfície do corpo humano, a pele, como elemento de criação artística. Além de trazer as questões sobre a importância do contato afetivo, do carinho, da ternura e do toque como fonte de vida, o trabalho também se propõe a questionar as ideias de modo complexo e aberto sobre abuso, violência e censura. Ver mais em http://grupotata.blogspot.com/p/espetaculos.html. 
O espetáculo Quando você me toca, estreou em outubro de 2018 , tendo como mote criativo a superfície da pele, suas sensações, e propondo-se a questionar diversos aspectos nos "modos" de tocar o outro. $\mathrm{Na}$ minha opinião, algumas das problemáticas que o espetáculo aborda trazem consigo uma exposição que eu não sabia se estava preparada para vivenciar neste contexto. Mas, conforme o grupo de bailarinos vinha experienciando reações e debates ${ }^{5}$ sobre o espetáculo nas outras escolas, concretizou-se em mim a ideia de que seria um momento de grande aprendizagem.

No dia 21 de agosto de 2019, no turno da manhã, o espetáculo é apresentado para todas as turmas do Ensino Médio (o que só foi possível pelo fato de algumas turmas estarem com poucos alunos no dia) da E.E.E.M Areal. No total, havia cerca de 110 alunos e, aproximadamente, 10 professores espectadores. A apresentação rendeu um entusiasmado debate com alunos e professores sobre as inspirações para a criação do espetáculo e as problemáticas que ele aborda: o toque é bom ou ruim? Qual é o limite do toque? O corpo da mulher é "tocável"? Quem pode tocar e ser tocado? O interessante foi que, entre os questionamentos que surgiram, um deles dizia respeito aos meus sentimentos em relação à exposição diante de "toda escola". Naquele momento, confirmei a relevância desta experiência como uma situação a ser analisada em meu TCC, algo que eu cogitava ainda antes da apresentação acontecer.

Como já mencionado, na pesquisa artística proporcionada pelo processo criativo e de exposição de Quando você me toca, a vivência de me apresentar para alunos não é nova. Porém, dançar este espetáculo no contexto da "minha" escola e para os "meus" alunos, deixou-me ansiosa como há muito tempo não ficava antes de uma experiência cênica. Ao final, estava bastante emocionada e, na conversa posterior à apresentação, pude expressar, brevemente, como aquele momento estava sendo importante para minha formação de professora-artista.

5 Um momento principal das apresentações nas escolas são as conversas, debates e questões que surgem após o espetáculo.
Por meio das mídias sociais (WhatsApp - grupo da turma), fiz um convite para uma turma do $3^{\circ}$ ano, na qual contextualizei a pesquisa e seu tema, perguntando, aos que haviam assistido à peça, se tinham interesse em participar de uma entrevista. Naquele momento, seis alunos manifestaram interesse. A entrevista ocorreu em 26 de agosto de 2019 e, como preparação da conversa, após elucidar detalhes sobre a pesquisa e a divulgação de conteúdo, busquei trazer informações do que se tratava uma pesquisa de TCC e, de forma resumida, qual era o tema e o foco principal do meu trabalho.

Depois da breve introdução, a entrevista iniciou com o questionamento: "Como vocês entendem o 'duplo papel' desempenhado pela professora ao atuar na escola como educadora e como artista?" Ao longo do texto, utilizo os nomes reais dos participantes, tendo consentimento dos mesmos e dos seus responsáveis para tal. A seguir, reflito sobre os dados separados pelas três categorias já citadas.

\section{O corpo da professora em exposição}

Ao analisar o que é proposto no documento oficial Parâmetros Curriculares Nacionais/Arte (BRASIL,1997) para o ensino de dança na Educação Básica, Falkembach (2017) destaca a indicação de que os conteúdos apresentados pelo docente devem estar baseados em três eixos - "executar, fazer e apreciar" - e, nesse sentido, o que é produzido em sala de aula deve, necessariamente, passar pelo exercício de ser apreciado. Porém, a autora adverte: no momento em que o documento aborda a "capacidade de olhar", não menciona a condição de ser "olhado" (FALKEMBACH, 2017, p. 106).

A noção de exposição, ligada a uma possível fragilidade do corpo exposto da professora-artista, é uma questão que aparece no momento inicial da entrevista com os alunos, pois para eles, estar exposto pode, em determinadas ocasiões, ser entendido como algo desconfortável. Ao trazer a proposta de dança para dentro da escola, seja em forma de projeto desenvolvido em turno inverso às atividades de classe, ou como conteúdo do com- 
ponente curricular da disciplina de Educação Física, acompanho as aprendizagens dos alunos, partilho corporalmente das atividades, demonstro os movimentos, proponho o improviso, dou exemplos que partem da minha corporeidade, ou seja, também estou sendo observada ao lecionar uma aula.

Mas, será que quando a professora está em cena em frente aos seus alunos, a dança de sala de aula é a mesma dança que se processa nos espaços cênicos convencionalmente ocupados por artistas da dança? Essa dança que a professora traz no seu corpo e que se expressa em cena, teria o mesmo sentido, ou objetivo, da dança que ela executa durante a docência? A aluna Diulia traz, em sua primeira fala, questões sobre essa condição:

[...] achei bem corajoso da tua parte, porque não é qualquer professor que gostaria de se expor e tu te expôs muito [...] tem muito tabu com o toque. Se eu tivesse no teu lugar, por mais legal e que a gente interaja com todo mundo, eu ficaria com aquela sensação também de estranheza, sabe? (Depoimento Diulia Moreira, 26/08/2019).

A visibilidade de estar em cena, para mim, traz indícios de que podemos, como professores-artistas, desconstruir pré-conceitos do senso comum, como as figuras de "professor intocável" e de "artista intocável", relacionadas às ideias de que para ser professor é necessário uma conduta entendida como moralmente superior às demais pessoas, o que implica não se deixar em exposição e não demonstrar fragilidades, entre outros comportamentos e, de que para ser artista é necessário ter um dom atribuído a poucos, algo inalcançável à maioria das pessoas.

Para Icle e Bonatto (2017) a estrutura do contexto escolar, física e de poder, contribui para garantir "a manutenção das formas de ser e estar nesse espaço, constituindo-se como instrumentos de controle tanto sobre os estudantes quanto sobre os professores", ou seja, cada um representa o seu papel "seguindo parâmetros culturalmente legitimados" segundo os quais a postura da figura do professor é "à frente da classe" (ICLE; BONATTO, 2017, p. 22).
A aluna utiliza os termos "corajoso", "tabu" e "estranheza", para expressar que "não é qualquer professor que gostaria de se expor". Luiza aborda de forma assertiva a ideia de postura docente, quando narra: [...] é por que, às vezes, algumas pessoas criam uma ideia do professor, sei lá, não faz "tal tipo de coisa" [...] a gente não tá acostumado a te ver fazendo isso [...] (Depoimento Luiza Soares, 26/08/2019).

Para Marques (1999; 2014), o professor de dança não deve ser apenas aquele que "apresenta" como é sua arte, o que a dança pode/deve proporcionar, mas sim, ser a própria matéria da arte, ser a própria fruição, portanto seu papel não seria "somente o de um intermediário entre estes mundos - a dança, a escola, a sociedade - ele seria também uma das fontes vivas para experimentarmos de maneira direta esta relação" (MARQUES,1999, p. 61).

Ao abordar questões referentes aos processos de ensino-aprendizagem e suas reverberações, Velloso (2014, p. 226) considera que o professor que permite ser "atravessado no corpo por práticas artísticas de modo a afetar, de outros modos, outros corpos e o seu próprio modo de ensinar", pode educar, através de sua arte "outros modos de mediar o ensino em dança".

Kethelen, uma estudante que teve um tempo maior de contato com a minha docência na escola, declara que "não senti nenhuma estranheza, porque eu participava do projeto de dança [...], eu já assisti também a Carol se apresentar em outros espetáculos, então não foi uma coisa muito impactante [...]". Porém, mesmo que já tenha me assistido em oportunidades em que estive na cena fora da escola, conclui que [...] querendo ou não é uma exposição, tu não se sente segura em se expor pra todos os alunos, alguns tu tem menos intimidade [...](Depoimento Kethelen Bilhalva, 26/08/2019).

Ao refletir sobre esta fala, penso que a aluna traz o termo "segura" pelo tema do espetáculo ser a partir do toque, algo íntimo e que se afasta, dependendo do contexto, da esfera da segurança ou da previsibilidade em "ser professor" na escola. De forma indireta, traz a ideia de que a exposição é intensificada em tal ocasião, pois alguns 
alunos têm "menos intimidade" comigo, pela questão de tempo de convivência ou das atividades que desenvolveram no âmbito da dança na escola.

Nessa perspectiva, a cena gera uma situação de "perigo" por mostrar um "eu" que antes estava preservado. Para Falkembach (2017) esse perigo está relacionado ao "medo do descontrole no governo de si mesmo e no governo dos outros" e questiona:

Por que é na dança que se perde o controle? Por que é na dança que os alunos "não se sentem à vontade"? Participar das aulas e presenciar o múltiplo jogo de relações entre alunos, alunas e professoras me encaminha para pensar que, na aula de dança, o corpo que é visto está exposto. Cria-se algo que é considerado expor-se em vários sentidos: deixar-se ver, exibir, tornar evidente e conhecido, ou mesmo posto a perigo (daí o medo). Há, assim, resistência dos alunos à exposição. (FALKEMBACH, 2017, p. 110).

Nesse sentido, ao me permitir vivenciar a condição de ser observada, acredito colocar-me, em certa medida, na condição dos alunos, quando observados nas aulas de dança.

\section{Feição de artista}

Num segundo momento da entrevista, solicitei aos participantes que descrevessem oralmente suas reflexões sobre a presença da professora em cena. Expliquei a eles que a questão tinha relação com a primeira pergunta disparadora, e propus: "Fale sobre as sensações e os questionamentos que surgiram durante a apreciação do trabalho Quando você me toca, em relação à presença da professora em cena". Naquele momento surgiu outra noção que alguns já tinham mencionado, mas que, após este último estímulo, aparece de forma mais evidente nas narrativas orais dos alunos: a noção de presença cênica, o que parece ser entendido por eles como sinônimo de um "olhar de artista" ou "feição de artista".

Por parte dos estudantes, alguns dos quais haviam me visto dançar em sala de aula, na condição de professora, evidenciou-se uma compreensão de que, ao me colocar em cena, eu assumi, efetivamente, a condição de artista. Nas palavras de Diulia "ali em cima não é a professora, sabe, o olhar que ela remete é o mesmo olhar que todos os outros artistas [...] bem diferente da professora de sala de aula" (Depoimento Diulia Moreira, 26/08/2019). A fala de Diulia é relativa ao papel interpretado em cena, demonstrando sua compreensão de que ali estou exercendo minha condição de artista, que me permite ser "outras", além da professora da sala de aula. Nesse sentido, ,nos parece que a cena ensina "a dimensão pedagógica é inerente à arte e, com efeito, não existe processo criativo que não contenha em si uma dimensão pedagógica" (ICLE, 2012 apud BALDI, 2018, p. 12).

Quando trabalhei com tarefas para o desenvolvimento da presença cênica no projeto de dança na escola, percebia a necessidade de fazer com que os alunos entendessem o que era o estado de "aqui e agora", um "estar" do corpo que não necessariamente vem do movimento, mas sim de uma condição energética do corpo. Os jogos de Viewpoints (BOGART, 2011) ajudavam a aperfeiçoar essa habilidade de concentração e conexão com o grupo. Eram momentos em que eu experienciava e "jogava" com eles, mas me prendia mais ao ato de observar como cada aluno chegava nesse estado cênico do que a minha atuação artística em aula.

Wellinton, ao falar sobre ver a professora em cena, admite ter se surpreendido e traz uma questão similar à de Diulia:

[...] foi tipo meio que um choque quando eu vi a professora pela primeira vez lá dançando, tipo, com aquele olhar de artista... Querendo ou não a feição muda muito, tipo, tu tem uma feição quando é professor, uma feição quando é artista [...]. (Depoimento Wellinton Borges, 26/08/2019).

Interessante perceber que o aluno traz o termo "feição" de quando se é professor, e a feição do artista, o "olhar de artista". Para mim, o que Wellinton, busca expressar não é a existência de uma "feição" estereotipada de professor, feição que determinaria como um docente deve ser ou se comportar no exercício profissional. Mas sim, que 
existe um modo diferente de estar no mundo no momento da cena (que ali sua professora encarna), ou seja, um interpretar ou, até mesmo, interpretar-se, que, para ele, "muda muito" a feição do sujeito.

Refletindo sobre a sua fala, penso que nas minhas propostas de aula, quando trago ideias aos improvisos, criações, e outros exercícios práticos em sala, das discussões e dos estudos teóricos sobre os temas da dança, utilizo também das minhas experiências de palco.

Para Strazzacappa (2011), a figura do professor-artista está relacionada aos "entre" dos processos de ensino/criação da sua experiência, colocando que "para ensinar arte, é necessário fazer arte, mantendo-nos sempre próximos àquilo de que somos feitos, isto é, próximos à nossa essência, à nossa materialidade artística" (STRAZZACAPPA, 2011, p. 145).

Nas narrativas dos alunos sobre o olhar, a feição, enfim, o "jeito diferente" que me apreciaram em cena, Luã coloca em suas primeiras falas que a professora "mostra um pouquinho da artista que é", algo que Luiza aborda como o "outro lado da professora".

A pesquisadora Rosana Paste (2017), na tese intitulada Artista-professor: cartografia e processo, refere-se a este "outro lado da professora" como integrante de um processo de contaminações e agenciamentos do artista que também exerce a profissão docente. No entanto, é interessante pensar nas contaminações do professor que escolhe exercer funções artísticas e, além disso, na possibilidade da não polarização entre arte e docência, ao entender ser viável a comunhão das práticas artísticas e pedagógicas. Este "outro lado da professora" pode ser entendido como uma de suas competências profissionais: ensinar e mediar a construção de conhecimentos artísticos, o que implica, dentre várias funções, atuar artisticamente.

Em meio aos pontos norteadores que instigaram os depoimentos e reflexões dos alunos, uma questão surgiu em suas narrativas: que quem leciona dança, ou faz faculdade de dança, não necessa- riamente é ou deveria ser artista. Diulia relata que "a gente sabe que tu é professora, [...] até mesmo porque tu dava as coreografias pra gente, mas é diferente [...]". Isso me inquietou bastante, pois não esperava que surgisse essa questão partindo deles, então lancei a eles a seguinte provocação: "vocês sabem que eu faço uma faculdade de dança, que eu sou professora de dança, mas pra vocês é diferente eu ser uma professora de dança e eu dançar?" Imediatamente os meninos debatem:

Wellinton: mais ou menos... Porque tem [...] tem uma certa diferença entre tu lecionar, tu ensinar aquilo e praticar aquilo no teu dia a dia... Luã: Exatamente... tu pode ensinar uma pessoa a dançar, mas tu pode não se apresentar, entendeu?!

Na reflexão que os alunos expõem podemos compreender que está indiretamente contemplada a ideia de que o professor de Dança, ou melhor, o professor de Arte, geralmente não atua como artista. Em geral, na experiência dos alunos, é mais comum que o professor que ensina arte (nesse caso, na escola) não necessariamente deva ser um artista, o que para eles significa que "não pratica no dia a dia" e "pode não se apresentar".

Essa discussão é recorrente nos textos de Marques (1999; 2003; 2014), que discorre sobre as distinções que ainda são feitas no campo da Educação das competências do professor de arte e do artista, questionando se, ao diferenciar tão radicalmente estas funções, não estaríamos reproduzindo "o preconceito socialmente constituído de que ser professor é mais fácil, uma carreira com exigências menores" incidindo na máxima "quem sabe faz, quem não sabe ensina?” (MARQUES, 2014, p. 233).

Para a autora, é costumeiro haver uma diferenciação de status entre as formações de bacharelado e de licenciaturas, que tem relação com a concepção senso comum de que as licenciaturas teriam menor importância, pois a genialidade criativa seria uma característica de artistas e não de professores.

Aparentemente, quando os alunos recorrem a essas questões, não necessariamente seus depoi- 
mentos carregam essa ideia do que "quem sabe faz, quem não sabe ensina", mas transparece uma certa surpresa, pelo fato de não terem tanta compreensão de tudo que engloba o curso de Dança - Licenciatura, como diz Diulia: "[...] acho que tem muita diferença também porque tem gente que faz a faculdade, mas não dá aula [...] às vezes só dança, mas não dá aula. Tu faz os três: faz a faculdade, dança (cenicamente) e dá aula". Quando Diulia traz a possibilidade de fazer faculdade e não dar aula é possível que este pensamento esteja relacionado ao bacharelado.

As provocações dos estudantes fazem-me voltar a atenção para a minha formação em Dança - Licenciatura, que tem como proposta dar suporte formativo para a construção de um saber híbrido, preparando um perfil de professor-artista-pesquisador (PPC, Curso de Dança - Licenciatura UFPel, 2013). Sobre isso, Luã e Luiza debatem:

Luã: É tipo Kit completo, entendeu? (risos) [...] ela aprende, ensina (risos) e, assim, tudo! [...] E também recebe o olhar do aluno, que tu...Que ela é professora e aluna ao mesmo tempo, então... Luiza: É aquela coisa, enquanto a gente tá ensinando, a gente tá aprendendo, a gente tá... é uma troca, certo?!

Para Luã e Luiza, a partir do contexto em que eles se encontram, representar um "kit completo" é sinônimo de ser docente, ser artista e ser aluna, ou seja, dar conta de variadas funções, deixando que essas funções interfiram umas nas outras. No caso, eles se referem especificamente ao meu papel de aluna-artista no espetáculo Quando você me toca, levando em conta a presença na escola e o papel desempenhado pela professora-diretora do trabalho, Maria Falkembach. Penso que nem todos ali tiveram essa "dimensão" de entendimento, mas cabe destacar a capacidade de reflexão dos alunos que se envolveram na pesquisa.

Com o objetivo de problematizar a noção de professora-artista, este texto busca levantar refle- xões acerca do fazer artístico-pedagógico em dança na Educação Básica. Com o desenvolvimento da investigação, foi possível reconhecer e compreender de forma ampliada a contínua formação docente que envolve o fazer profissional de uma professora-artista da Dança em atuação no ambiente escolar. E, ainda, identificar fatores artístico-pedagógicos que agem como influenciadores nos processos de ensino e aprendizagem da dança na escola, como, por exemplo, a experimentação, junto aos alunos, de conhecimentos adquiridos nas vivências da docente nos bastidores, na cena e no público em trabalhos de dança.

Ao me permitir investigar a vivência artística do espetáculo Quando você me toca reconhecendo-a como experiência artístico-pedagógica relevante a ser considerada como situação-chave para a pesquisa, vou ao encontro do que Marques (2014, p. 235) entende como condição necessária para ser/ estar professor-artista na escola, sendo o docente aquele que "educa dançando e dança educando, consciente das duas ações fundidas que exerce".

$\mathrm{Na}$ perspectiva dos autores estudados (BORN, 2012; DEBORTOLI, 2011; MARQUES, 2014) entendo que ser artista, fazer sua arte e trazê-la como meio pedagógico é condição essencial na atuação do professor-artista.

Entretanto, ainda que, no contexto escolar, a figura de professor-artista seja pouco predominante ou difundida, é importante ressaltar que quando trago essa discussão para a pesquisa, não pretendo fazer um julgamento sobre professores que optam por não atuar artística ou cenicamente na escola. Certamente, não procuro fazer um juízo de "valor docente" com a pesquisa.

Por se tratar de uma investigação de si (JOSSO, 2007), após as entrevistas constato que atuar como professora-artista da dança na escola é uma possibilidade de tornar o ensino mais sensível e potente.

Buscar essa comunhão entre os papeis de docente e artista dentro da instituição escolar pode aproximar as realidades de professores de arte e educandos, uma vez que ambos estão olhando e são olhados, fazendo com que se crie, além de instigar que os alu- 
nos atuem artisticamente, também uma relação de cumplicidade. Nesse sentido, acredito que se isto é uma realidade concreta para mim, pode ser ou pode vir a ser para tantos outros, que compartilham da mesma ou de concepções similares sobre ensino de arte.

Assim, a experiência aqui compartilhada espera instigar outros professores do ensino de dança na escola, a pensar sobre docência em dança a partir dos seus fazeres artístico-pedagógicos, sugerindo uma reflexão de como suas produções artísticas podem ser uma via de ensino e aprendizagem aproveitado pelo docente, na medida em que esses modos de ser professor-artista, torna-se um meio de educação e de problematização do fazer artístico-pedagógico na Educação Básica.

\section{Referências}

BALDI, Neila Cristina. Diários e inventários como processos formativos em dança. Revista Brasileira de Pesquisa (Auto)Biográfica, Salvador, v. 03, n. 08, p. 711-725, mai./ago. 2018. Disponível em: http://www.revistas.uneb.br/index.php/rbpab/article/ view/4446. Acesso em: 7 ago. 2019. DOI: http://dx. doi.org/10.31892/rbpab2525-426X.2018.v3.n8.p711725 .

BOGART, Anne. Os Viewpoints e a Composição: o que são? A Preparação do Diretor. São Paulo: Martins Fontes, p. 25-32, 2011.

BORN, Patriciane. Entre a docência e o fazer artístico: formação e atuação coletiva de professoras artistas. 139f. Dissertação (Mestrado em Educação) - Programa de Pós-Graduação em Educação, Faculdade de Educação, Universidade Federal do Rio Grande do Sul, Porto Alegre, 2012. Disponível em: https://www.lume.ufrgs.br/handle/10183/69926. Acesso em: nov. 2019.

BRASIL. Secretaria de Educação Fundamental. Parâmetros curriculares nacionais: arte / Secretaria de Educação Fundamental. - Brasília: MEC/SEF, 1997.
DE ARAÚJO, Valéria Gianechini. Uma mirada sobre o artista-docente. in 7a. Reunião Científica de Pesquisa e Pós-Graduação em Artes Cênicas, 2012, Porto Alegre. Anais da Abrace, v. 13, n. 1, 2012. Disponível em:

https://www.publionline.iar.unicamp.br/index.php/ abrace/issue/view/96. Acesso em: 04 out. 2019.

DEBORTOLI, Kamila Rodrigues. Professor e artista ou professor-artista?. DAPesquisa, Florianópolis, v. 6 , n. 8, p. 091-098, 2011. ISSN 1808-3129. Disponível em: http://www.revistas.udesc.br/index.php/ dapesquisa/article/view/13995. Acesso em: 30 out. 2019.

FALKEMBACH, Maria Fonseca. Corpo, Disciplina e Subjetivação nas Práticas de Dança: um estudo com professoras da rede pública no sul do Brasil. Porto Alegre: UFRGS, 2017. 241 f. Tese (Doutorado em Educação) - Programa de Pós-Graduação em Educação, Universidade Federal do Rio Grande do Sul, Porto Alegre, 2017.

ICLE, Gilberto; BONATTO, Mônica Torres. Por uma pedagogia performativa: a escola como entrelugar para professores-performers e estudantes-performers. Cadernos CEDES, Campinas, v. 37, n. 101, p. 7-28, jan.-abr., 2017. Disponível em: http://www. scielo.br/pdf/ccedes/v37n101/1678-7110-ccedes-37-101-00007.pdf. Acesso em: 29 ago. 2019.

JOSSO, Marie-Christine. A transformação de si a partir da narração de histórias de vida. Educação, Porto Alegre/RS, ano XXX, n. 3 (63), p. 413-438, set./dez. 2007. Disponível em: http://revistaseletronicas.pucrs. br/ojs/index.php/faced/article/view/2741 Acesso em: 30 mar. 2019.

JOVCHELOVITCH, Sandra; BAUER, Martin W. Entrevista Narrativa. In: BAUER, Martin W.; GASKELL, George. (Orgs.) Pesquisa qualitativa com texto, imagem e som: um manual prático. 13. ed. Petrópolis, Rio de Janeiro: Vozes, 2015. p. 90-113. 
MARQUES, Isabel. Ensino de dança hoje: textos e contextos. São Paulo: Cortez, 1999.

MARQUES, Isabel. Dançando na Escola. São Paulo: Cortez, 2003.

MARQUES, Isabel. O artista/docente: ou o que a arte pode aprender com a educação (3). OuvirOUver. Uberlândia, v. 10, n. 2, p. 230-239 jul.dez. 2014. Disponível em: https://doi.org/10.14393/OUV14-v10n2a2014-4 Acesso em: ago. 2019.

PASTE, Rosana. Artista-professor: cartografia e processo / Rosana Paste. 2017. 167f. Tese (Doutorado em Educação) - Universidade Federal do Espírito Santo, Centro de Educação. Disponível em: http:// repositorio.ufes.br/handle/10/8521. Acesso em set. 2019.

PEROBELLI, M. H. Desafios na formação do artista-docente contemporâneo. in: 6 Reunião Científica de Pesquisa e Pós-Graduação em Artes Cênicas, 2011, Porto Alegre. Anais da Abrace. p. 1-6. Disponível em: http://www. portalabrace.org/vireuniao/pedagogia/58.\%20Mariene_Perobelli.pdf. Acesso em: 3 out. de 2019.

STRAZZACAPPA, Marcia. A dança e a formação do artista. In: MORANDI, Carla; STRAZZACAPPA, Marcia (Org.) Entre a arte e a docência - a formação do artista da dança, Campinas, SP: Papirus, 2006.

STRAZZACAPPA, Márcia. Daquilo de que somos feitos ou Debruçando-me sobre o processo de criação da obra Sobre Mulheres e Lobos. In: ALBANO, Ana Angélica; STRAZZACAPPA, Márcia (Org.) Entrelugares do corpo e da arte. Campinas, SP: FE/ UNICAMP, 2011.

UNIVERSIDADE FEDERAL DE PELOTAS. Curso de Dança-Licenciatura: Projeto Pedagógico. Disponível em:https://wp.ufpel.edu.br/danca/. Acesso em: set. de 2019.
VELLOSO, Marila. Intensificação sensorial em espaços de compartilhamento: o docente e o artista vivenciando continuidade em processos de criação. OuvirOUver. Uberlândia v. 10, n. 2, p. 220-228 jul./ dez. 2014. Disponível em: https://doi.org/10.14393/ OUV14-v10n2a2014-3. Acesso em: 29 out. 2019.

Recebido: 10/01/2021

Aceito: $30 / 03 / 2021$

Aprovado para publicação: 28/05/2021

Este é um artigo de acesso aberto distribuído sob os termos de uma Licença Creative Commons Atribuição 4.0 Internacional. Disponível em: http://creativecommons.org/licenses/by/4.0.

This is an open-access article distributed under the terms of the Creative Commons Attribution License 4.0 International. Available at: http://creativecommons.org/licenses/by/4.0.

Ce texte en libre accès est placé sous licence Creative Commons Attribution 4.0 International. Disponible sur: http://creativecommons.org/licenses/by/4.0. 